\title{
Structural features of the ovaries of texas quail in the experiment
}

\author{
Natalia Saenko ${ }^{1, *}$, Vladimir Lemeshchenko ${ }^{1}$, Vitaly Sokolov ${ }^{1}$, Elena Nekhaychuk $^{1}$, and \\ Julia Saenko ${ }^{1}$ \\ ${ }^{1}$ Federal State Autonomous Educational Institution "Crimean Federal University named after V. I. \\ Vernadsky", 295007, Academician Vernadsky Avenue, 4, Simferopol, Russia
}

\begin{abstract}
The article analyzes the postembryonic organogenesis of the ovaries of Texas quail when using biologically active substances. A set of morphological techniques is used. It was found that the use of probiotic in combination with succinic acid to Texas quail at the age of 5-45 days caused intensive growth and development of their ovaries. Probiotic preparation "Sporovit" and succinic acid do not cause pathological changes in the micromorphological structure of the reproduction organs of quails.
\end{abstract}

\section{Introduction}

Today, quail farming is one of the youngest and most rapidly developing poultry industries in the Russian Federation. Scientists note the special biological characteristics of quails: high growth rate, early oviposition (30-40 days), small size, precocity, intensive metabolism, which causes a fairly high body temperature, and this helps protect birds from a variety of infectious diseases [1-3]. The use of quails is not limited only to the agricultural direction, their biological features allow us to find in them the object of laboratory research [4].

While quails have a large number of advantages compared to other poultry, they can also have disadvantages. The main disadvantage is the significantly high cost of quail production, which is due to the high costs of their maintenance and breeding. The intensity of growth of quail and a high level of egg productivity of females is ensured when they are fed with high-quality feed containing all the necessary nutrients at the proper level. Currently, in veterinary medicine, biologically active substances of various groups are used to increase the viability of young poultry for therapeutic and preventive purposes [5-7]. Probiotics, which action is supported by the mechanisms of protection of the macroorganism from harmful effects of the ecosystem, that have been developed in the course of evolution, deserve special attention [8-12].

With high egg productivity of quails, the biological features of these birds are understudied. The reproductive organs of ducks, turkeys, and chickens have been thoroughly studied, while the morphology of the sexual apparatus of quails has not been sufficiently examined. The structure and development of egg-forming organs in quails have

\footnotetext{
*Corresponding author: nvsaenko@list.ru
} 
not been studied enough, and the existing works in this area reveal only fragments of these aspects [13-19].

Considering the above, it becomes relevant to study the morphology of the organs of the reproductive system of quails under the influence of probiotic "Sporovit" and succinic acid. The purpose of this work was to study the postembryonic organogenesis of the ovary of Texas quail when using the probiotic "Sporovit" and succinic acid.

\section{Method of research}

The objects of research were quails of the Texas breed, aged from 5 to 55 days. The birds were divided into three groups (by $n=12$ in each group). For feeding in the first 14 days, a full value granulated feed "Start" was used for young birds, at the age of 15-28 days mixed feed "Rost" was used, and from 28 days of age, mixed feed "Finish" was used, all feeds corresponded to the age needs of birds. Moreover, the control group received only feed and water, first experienced additionally injected 11 of water $3 \mathrm{ml}$ of probiotic "Sporovit", the second test $-3 \mathrm{ml}$ probiotic "Sporovit" and $0.05 \mathrm{~g}$ of succinic acid/ 11 of water.

To find out the effect of the probiotic "Sporovit" and succinic acid on the postembryonic organogenesis of the ovaries of Texas quail, the following research methods were used: clinical, anatomical preparation, morphometric, histological, and statistical. Behavioral responses, appetite, condition of mucous membranes and feather cover, and fatness of quails were assesed clinically. On the 5th, 15th, 35th, 45th and 55th days, the live weight of poultry was determined on the scales of "Technovagi TVE" with an accuracy of 0.01 .

Then the birds were subjected to euthanasia by acute exsanguination $(n=9$ in each group). Postmortem examination was performed, and the ovaries with the oviduct were taken. After extracting the reproductive organs, their morphometric examination was fulfilled. The mass of organs was determined by weighing with an accuracy of 0.00001 grams. Morphometry of the abdominal cavity and reproductive organs was carried out with the use of a ruler with a graduation scale of $0.1 \mathrm{~mm}$ and a thread.

Then the reproductive organs were taken out and fixed first in 5\% (7 days), and then in $10 \%$ aqueous solution of formalin (7 days), where they were stored during the research. Paraffin sections were prepared, which were stained with hematoxylin-eosin according to the generally accepted technique, followed by microscopy on a microscope Mikmed 5 and micromorphometry using an MOV $115 \mathrm{x}$ eyepiece micrometer. Statistical methods were used for processing experimental data in order to determine the reliability of changes in values. Statistical processing of the obtained results was carried out by the generally accepted method of variation statistics on a personal computer using the Microsoft Excel 2010 application (Microsoft Corp. USA) and the statistical data analysis package Statistica 8.0 for Windows.

\section{Research results}

Clinical observations of quails while using probiotic "Sporovit" and succinic acid show that their influence on the overall clinical condition of birds is insignificant. On the usage of probiotic preparation "Sporovit", the feather cover was formed faster and was of high quality in the first periods of the experiment. But succinic acid increased the activity and mobility of animals throughout the study periods. The live weight of quail in experimental 
group No 1 significantly differs from one of the control group, especially at the age of 15 and 35 days (table 1).

Data on average daily increases in live body weight of quails show that in the first period (15-35 days), the highest absolute and average daily increase in live weight was observed when using the probiotic preparation "Sporovit" (Fig. 1). In the second period (35-45 days), the use of this preparation had a negative impact on the absolute and average daily increase in body weight, the values were the lowest of all groups. The highest increases in body weight were observed in the control group. In the third period (45-55 days), the best result was shown by the use of the probiotic preparation "Sporovit" in combination with succinic acid.

Table 1. Dynamics of live weight of Texas quail while using probiotic "Sporovit" and succinic acid, $g$

\begin{tabular}{|c|c|c|c|c|}
\hline \multirow{2}{*}{ Groups } & \multicolumn{4}{|c|}{ Age } \\
\cline { 2 - 5 } & $\mathbf{1 5}$ days & $\mathbf{3 5}$ days & $\mathbf{4 5}$ days & $\mathbf{5 5}$ days \\
\hline Control & $26.90 \pm 2.92$ & $123.24 \pm 13.45$ & $200.87 \pm 11.13$ & $237.33 \pm 12.15$ \\
\hline $\begin{array}{c}\text { Experimental } \\
\text { No 1 }\end{array}$ & $46.24 \pm 6.05^{* *}$ & $162.40 \pm 14.55^{* *}$ & $186.03 \pm 16.72$ & $238.80 \pm 14.72$ \\
\hline $\begin{array}{c}\text { Experimental } \\
\text { No 2 }\end{array}$ & $40.86 \pm 5.82^{* *}$ & $142.46 \pm 13.59$ & $201.70 \pm 13.23$ & $256.83 \pm 4.04$ \\
\hline Average & $38.00 \pm 3.86$ & $142.70 \pm 8.95$ & $196.20 \pm 7.39$ & $244.32 \pm 6.45$ \\
\hline
\end{tabular}

$* *$ Acc $\leq 0.05$

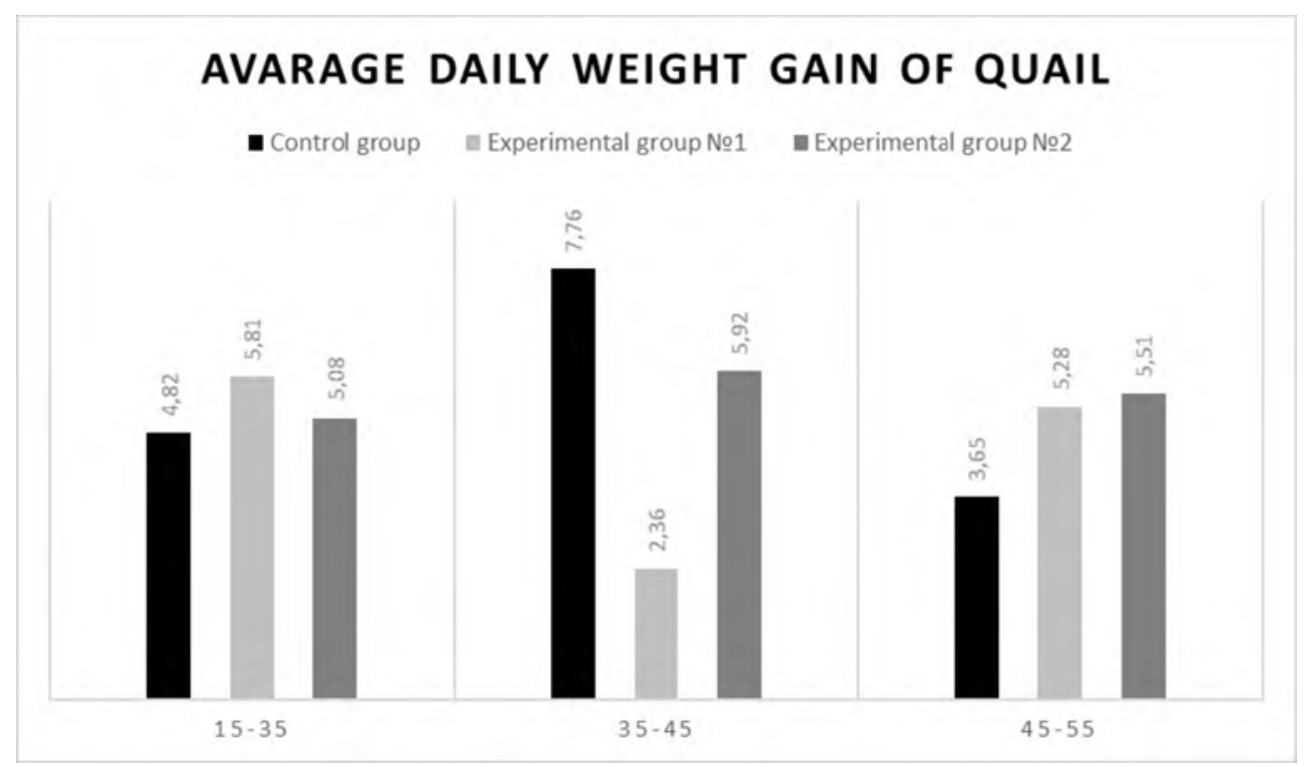

Fig. 1. Avarage daily weight gain of quail.

Thus, the average daily weight gain had the most stable values in all age periods of the experiment in quails of experimental group No 2, while in the other two groups there were abrupt changes in the intensity of growth of the birds. 
In female quails, the sexual system is unpaired left-sided, consisting of an oviduct and ovary, which has the form of a lumpy formation. In males, the testes are bean-shaped, topographically located under the lumbosacral bone. The right testis is more elongated, the left one is rounded.

During the study, morphometry of the sexual apparatus of quails of 15, 35, 45, 55-dayold age was performed, the results of which are shown in table 2 .

At the age of 15 days, the weight of the ovaries in the control group varies between $0.001610-0.02430 \mathrm{~g}$, and the average weight is $0.01 \pm 0.01 \mathrm{~g}$. The mass of ovaries of birds in experimental group No 1 is $100 \%$ higher (from 0.01530 to $0.02240 \mathrm{~g}$ ), and in experimental group No 2 is $200 \%$ higher (from 0.008 to $0.036 \mathrm{~g}$ ) than in the control group, and $100 \%$ higher than in experimental group No 1.

At the same time, the length of the ovaries of quails in the control group is within 0.8 $0.9 \mathrm{~cm}$, this is on average $0.85 \pm 0.03 \mathrm{~cm}$. In experimental group No 1 , the length of the ovaries is the same as in the control group (from 0.80 to $0.90 \mathrm{~cm}$ ), and in experimental group No 2 is $14.2 \%$ lower than in the control and experimental groups. The width of the ovaries of quails in the control group ranges from 0.30 to $0.40 \mathrm{~cm}$ and on average is $0.35 \pm 0.03 \mathrm{~cm}$. In birds of experimental group No 1 , the width of the ovaries is $28.60 \%$ higher (from 0.40 to $0.50 \mathrm{~cm}$ ), while in experimental group No 2 is $14.30 \%$ higher (from 0.30 to $0.50 \mathrm{~cm}$ ) than in the control group, but $14.30 \%$ lower than in experimental group No 1 . In the control group of quails, the ovarian volume reaches $0.90-1.40 \mathrm{~cm}^{3}$, which is on average equal to $1.15 \pm 0.14 \mathrm{~cm}^{3}$. In experimental group No 1 , the volume of ovaries is $21.70 \%$ lower (from 0.7 to $1.1 \mathrm{~cm}^{3}$ ), and in experimental group 2 is $13.00 \%$ lower (from 0.70 to $1.20 \mathrm{~cm}^{3}$ ) than in the control group, and $8.70 \%$ lower than in experimental group No 1.

Table 2. Parameters of female quail ovaries

\begin{tabular}{|c|c|c|c|c|c|}
\hline \multirow{2}{*}{ 节 } & \multirow[b]{2}{*}{ Values } & \multicolumn{4}{|c|}{ Age } \\
\hline & & 15 days & 35 days & 45 days & 55 days \\
\hline \multirow{4}{*}{$\begin{array}{l}\overrightarrow{0} \\
\stackrel{\Xi}{0} \\
\overline{0}\end{array}$} & Weight, $g$ & $0.01 \pm 0.01$ & $0.06 \pm 0.00$ & $0.26 \pm 0.06$ & $0.42 \pm 0.19$ \\
\hline & Length, $\mathrm{cm}$ & $0.85 \pm 0.03$ & $1.35 \pm 0.09$ & $1.40 \pm 0.06$ & $2.95 \pm 0.75$ \\
\hline & Width, cm & $0.35 \pm 0.03$ & $0.55 \pm 0.03$ & $0.97 \pm 0.07$ & $2.34 \pm 0.83$ \\
\hline & Volume, $\mathrm{cm}^{3}$ & $1.15 \pm 0.14$ & $1.2 \pm 0.06$ & $1.95 \pm 0.03$ & $10.65 \pm 4.76$ \\
\hline \multirow{4}{*}{ 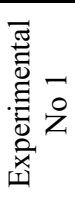 } & Weight, $g$ & $0.02 \pm 0.00^{* *}$ & $0.11 \pm 0.02 * *$ & $0.28 \pm 0.02$ & $1.55 \pm 1.09^{* *}$ \\
\hline & Length, $\mathrm{cm}$ & $0.85 \pm 0.03$ & $1.35 \pm 0.14$ & $1.36 \pm 0.20$ & $1.53 \pm 0.03$ \\
\hline & Width, cm & $0.45 \pm 0.03$ & $0.70 \pm 0.06$ & $1.05 \pm 0.10$ & $1.37 \pm 0.13$ \\
\hline & Volume, $\mathrm{cm}^{3}$ & $0.90 \pm 0.12$ & $1.45 \pm 0.20$ & $2.10 \pm 0.12$ & $2.77 \pm 0.56^{* *}$ \\
\hline \multirow{4}{*}{ 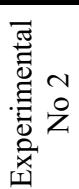 } & Weight, $g$ & $0.03 \pm 0.01^{* *}$ & $0.18 \pm 0.01^{* *}$ & $0.35 \pm 0.03$ & $4.36 \pm 2.34 * *$ \\
\hline & Length, $\mathrm{cm}$ & $0.73 \pm 0.09$ & $1.75 \pm 0.09$ & $1.30 \pm 0.12$ & $2.42 \pm 0.63$ \\
\hline & Width, cm & $0.40 \pm 0.06$ & $0.65 \pm 0.03$ & $1.10 \pm 0.15$ & $1.44 \pm 0.44$ \\
\hline & Volume, $\mathrm{cm}^{3}$ & $1.00 \pm 0.15$ & $1.73 \pm 0.23$ & $2.30 \pm 0.50$ & $6.30 \pm 3.05^{* *}$ \\
\hline
\end{tabular}

$* *$ Acc $\leq 0.05$

In 15-day-old quails of all groups, the ovarian mass varies within 0.008-0.036 g, their average mass is $0.02 \pm 0.01 \mathrm{~g}$. The length of the ovaries is in the range of $0.60-0.90 \mathrm{~cm}$, and the average length corresponds to $0.80 \pm 0.04 \mathrm{~cm}$. The width of the ovaries reaches $0.30-0.50$ $\mathrm{cm}$, with an average width of $0.40 \pm 0.03 \mathrm{~cm}$. The volume of the ovaries is $0.70-1.40 \mathrm{~cm}^{3}$, the average volume is $1.01 \pm 0.10 \mathrm{~cm}^{3}$. 
In 35-day-old quails of the control group, the ovarian mass varies from $0.059 \mathrm{~g}$ to $0.062 \mathrm{~g}$, which is $0.06 \pm 0.00 \mathrm{~g}$ on average. The quails of experimental group No 1 it is $83.00 \%$ higher (0.071-0.1450 g), and the quails of experimental group No 2 it is $200.00 \%$ higher (from 1.10 to $1.60 \mathrm{~g}$ ) than in the control group, and $117.00 \%$ higher than in experimental group No 1.

The length of the ovaries in the control group of quails is $1.20-1.50 \mathrm{~cm}$, and the average length is $1.35 \pm 0.09 \mathrm{~cm}$. In experimental group No 2, the length of the ovaries is the same as in the control group (from 0.80 to $0.90 \mathrm{~cm}$ ), and in experimental group No 2 is $29.60 \%$ lower than in the control and experimental No 1 groups.

It was also found that the width of the ovaries of the control group of birds varies from 0.50 to $0.60 \mathrm{~cm}$, the average width is $0.55 \pm 0.03 \mathrm{~cm}$. In experimental group No 2, the width of the ovaries is $27.30 \%$ higher (from 0.60 to $0.80 \mathrm{~cm}$ ), and in experimental group No 2 is $18.2 \%$ higher (from 0.60 to $0.70 \mathrm{~cm}$ ) than in the control group, but $19.10 \%$ lower than in experimental group No 1.

The control group of quails has an ovarian volume of 1.10 to $1.30 \mathrm{~cm}^{3}$, which is $1.20 \pm 0.06 \mathrm{~cm}^{3}$ on average. And the volume of ovaries in experimental group No 1 is $20.80 \%$ higher (from 1.10 to $1.80 \mathrm{~cm}^{3}$ ), while in experimental group No 2 is $44.20 \%$ higher (from 1.30 to $2.10 \mathrm{~cm}^{3}$ ) than in the control group and $23.40 \%$ higher than in experimental group No 1.

In all groups of 35-day-old female quails, the ovarian mass is within the range of 0.059$0.190 \mathrm{~g}$, their average weight is $0.12 \pm 0.03 \mathrm{~g}$. The length of the ovaries is in the range of $1.10-1.60 \mathrm{~cm}$, their average length is $1.38 \pm 0.13 \mathrm{~cm}$. The width varies from 0.60 to $0.80 \mathrm{~cm}$, and the average width is $0.68 \pm 0.05 \mathrm{~cm}$. The volume of the ovaries is $1.10-2.10 \mathrm{~cm}^{3}$, and the average volume is $1.53 \pm 0.25 \mathrm{~cm}^{3}$.

At the age of 45 days, quails of the control group have an ovarian mass in the range of $0.16-0.36 \mathrm{~g}$, which is on average $0.26 \pm 0.06 \mathrm{~g}$. In experimental group No 1 , the weight of ovaries of birds is $7.7 \%$ higher $(0.25-0.31 \mathrm{~g})$, in experimental group No 2 is $34.6 \%$ higher (from 0.29 to $0.39 \mathrm{~g}$ ) than in the control group, and $126.9 \%$ higher than in experimental group No 1.

Examining the length of the ovaries of individuals from the control group, we found that it is within the range of $1.30-1.50 \mathrm{~cm}$, and on average it is $1.40 \pm 0.06 \mathrm{~cm}$. The length of the ovaries in experimental group No 1 is $2.90 \%$ lower $(1.01-1.71 \mathrm{~cm})$, and in experimental group No 2 is $7.20 \%$ lower $(1.10-1.50 \mathrm{~cm})$ than in the control group, and $4.20 \%$ lower than in experimental group No 1.

The width of the ovaries of birds in the control group ranges from 0.87 to $1.10 \mathrm{~cm}$, and on average it is $0.97 \pm 0.07 \mathrm{~cm}$. Quails of experimental group No 1 have ovarian width by $8.20 \%$ higher $(0.90-1.25 \mathrm{~cm})$ than in the control group, and birds of experimental group by $13.40 \%$ higher (from 0.90 to $1.40 \mathrm{~cm}$ ) than in the control group, and by $5.20 \%$ higher than in experimental group No 1 .

The volume of the ovaries of the control group of quails is in the range from 1.89 to $2.00 \mathrm{~cm}^{3}$, and on average this corresponds to the value of $1.95 \pm 0.03 \mathrm{~cm}^{3}$. In experimental group No 1, the ovarian volume is $7.70 \%$ higher $\left(1.90-2.30 \mathrm{~cm}^{3}\right)$ than in quails from the control group, and quails from experimental group No 2 have the ovarian volume $17.90 \%$ higher $\left(1.69-3.30 \mathrm{~cm}^{3}\right)$ than in the control group and $10.20 \%$ higher than in experimental group No 1.

In 45-day-old quails of all groups, the ovarian mass is within the range of $0.16-0.37 \mathrm{~g}$, their average weight is $0.30 \pm 0.03 \mathrm{~g}$. The length of the ovaries of all individuals is $1.50 \mathrm{~cm}$, and their average length is $1.50 \pm 0.00 \mathrm{~cm}$. The width of the ovaries varies from 1.10 to 1.40 $\mathrm{cm}$, its average width is $1.25 \pm 0.15 \mathrm{~cm}$. The volume of the ovaries varies between $2.00-3.30$ $\mathrm{cm}^{3}$, and their average volume is $2.65 \pm 0.65 \mathrm{~cm}^{3}$. 
In 55-day-old quails of the control group, the ovarian mass varies significantly, from 0.31 to $8.41 \mathrm{~g}$, the average ovarian mass is $4.36 \pm 2.34 \mathrm{~g}$. In experimental group No 1 , the mass of ovaries of birds is $90.4 \%$ lower (from 0.20 to $0.80 \mathrm{~g}$ ), and in experimental group No 2 is $64.40 \%$ lower (from 0.43 to $3.73 \mathrm{~g}$ ) than in the control group, and $26.00 \%$ higher than in experimental group No 1.

The length of the ovaries in the control group is within the range of $1.70-4.20 \mathrm{~cm}$, which is on average $2.95 \pm 0.75 \mathrm{~cm}$. In experimental group No 1 it is $48.10 \%$ lower $(1.50-1.60 \mathrm{~cm})$ than in the control group, and in experimental group No 2 it is lower by $18.00 \%(1.60-3.67$ $\mathrm{cm})$, and in comparison with experimental group No 1 - higher by $30.10 \%$.

The width of the ovaries of quail in the control group was determined in the range from 0.90 to $3.77 \mathrm{~cm}$, on average it is $2.34 \pm 0.83 \mathrm{~cm}$. In experimental group No 1 it is $41.50 \%$ lower (from 1.10 to $1.50 \mathrm{~cm}$ ), and experimental group No 2 it is $3.40 \%$ higher (from 1.00 to $2.33 \mathrm{~cm}$ ) than in the control group, and $44.90 \%$ higher than in the experimental group No 1 .

Measurement of the ovarian volume of control group birds allowed to determine the variation from 1.70 to $3.60 \mathrm{~cm}^{3}$, and on average it is $0.42 \pm 0.19 \mathrm{~cm}^{3}$. In experimental group No 1, the volume of ovaries was $269.05 \%$ higher $\left(3.00-12.40 \mathrm{~cm}^{3}\right)$ than in the control group, and in experimental group No 2 was $93.10 \%$ higher $\left(2.40-18.90 \mathrm{~cm}^{3}\right)$, and $33.20 \%$ higher than in experimental group No 1.

All groups of quail at the age of 55 days have a mass of ovaries in the range of 0.20 $8.41 \mathrm{~g}$, and on average their mass is $0.99 \pm 0.03 \mathrm{~g}$. The length of the ovaries has values in the range of $1.50-2.00 \mathrm{~cm}$, and the average length is $1.65 \pm 0.08 \mathrm{~cm}$. The width of the ovaries varies from 0.90 to $1.50 \mathrm{~cm}$, and the average width is $1.17 \pm 0.11 \mathrm{~cm}$. The volume of the ovaries is within the range of $1.70-3.50 \mathrm{~cm}^{3}$, and the average volume is $3.72 \pm 0.42 \mathrm{~cm}^{3}$.

Histological studies have shown that at the age of 15 days the border of the cortical $(70 \%)$ and medullary (30\%) layers is even and expressed relatively clearly. In the cortical layer there are oocytes of the 1st order, around which the connective tissue is located (Fig. 2).

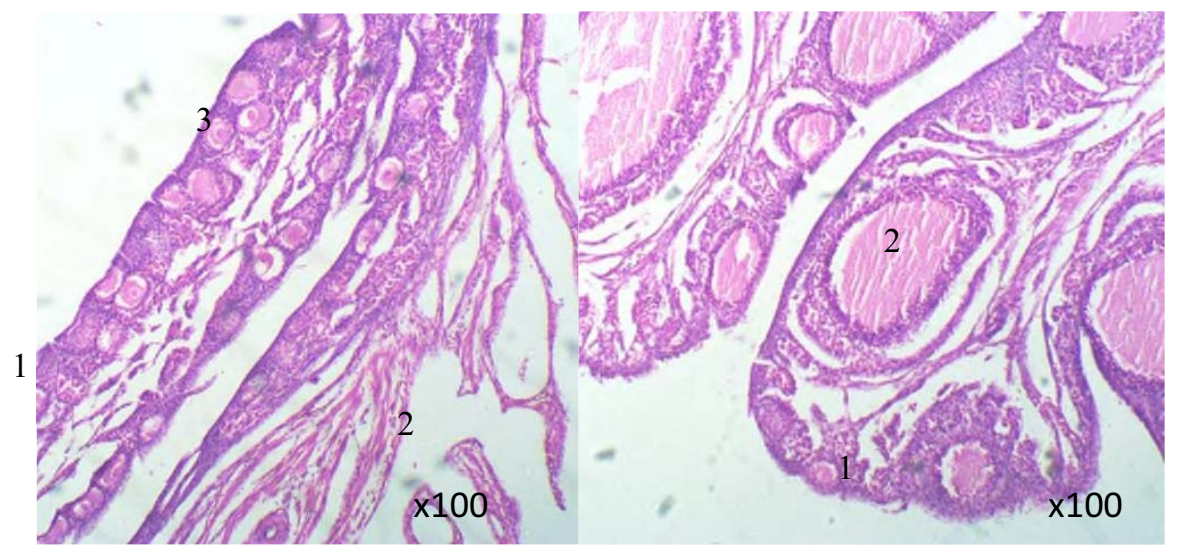

Fig. 2. Primary ovarian follicles of quail at the age of 15 days. 1 - cortical layer; 2-brain layer; 3-primary follicle.
Fig. 3. Quail ovarian Follicles at various stages development at the age of 35 days. 1-developing follicle; 2 - primary follicle.

Follicles form in the center of the ovary and along its periphery. The follicle wall consists of connective and epithelial tissues. The wall of primary follicles (during the growth period) is formed by a layer of squamous follicular epithelium. The oocytes in these follicles are 62 microns in diameter and contain a large nucleus. The cortical zone is formed of loose connective tissue and interstitial cells, which are oval or polygonal, containing both rounded and oval nuclei. The meninges contains blood vessels and nerves. On top of the 
cortical layer is the albuminous membrane (connective tissue), above it is a single-layer covering epithelium.

At the age of 35 days all follicles are formed, the border between the cortex and medulla is erased (Fig. 3). In the cortical zone there are follicles containing oocytes developing at different stages. Follicular epithelium constitute $75 \%$.

In quails at the age of 45 days, oocytes gradually begin to pass into the stage of slow growth, while the formation of the yolk shell occurs, follicular cells in the form of a "radiant crown" are located around it (Fig. 4). The follicular layer passes into the granulose layer, which cells are separated from the connective tissue surrounding it by the basement membrane. Near the follicular epithelium, ovarian tissues form a tecal sheath (the techa of the follicle) that forms the tecal glands.

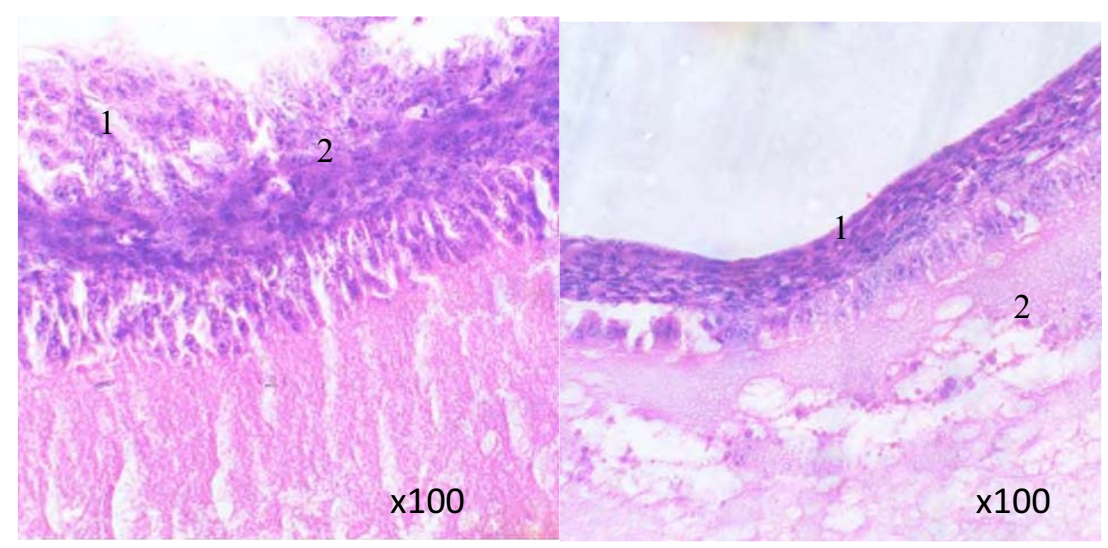

Fig. 4. The wall of the ovarian follicle of a quail at the age of 45 days. 1 - follicular cells in the form of a "radiant crown"; 2-yolk shell.
Fig. 5. The wall of the ovarian follicle of a quail at the age of 55 days. 1 - follicular epithelium; 2 - yolk

At the age of 55 days, quails from experimental group No 1 have oocytes in the period of slow growth (cytoplasmic). The wall of the follicle covering the oocyte during this period consists first of cubic, and then of highly prismatic cells (Fig. 5). They contain microvilli at the apical pole that penetrate the cytoplasm of the oocyte. During this period, the diameter of the oocyte is 2300 microns, and the core is 215 microns on transition from the slow growth stage to the rapid growth stage and reaches a diameter of $3 \mathrm{~mm}$.

In quails of experimental group No 2, oocytes are in the phase of rapid growth (trophoplasmic), at this time their diameters vary from $3-5 \mathrm{~mm}$ to $28-32 \mathrm{~mm}$, the core is flattened and has the form of a lens, located at the animalny pole. The yolk makes up the majority of the oocyte, the follicular epithelium is flattened, there are no microvilli, and the gaps between the cells are widened.

It follows that at the age of 15 days, the growth of ovarian follicles is noticeable only with histological examination. It is detected being uneven (in the center and with a transition to the periphery), and during this period, the cortical and cerebral layer of the gland are differentiated clearly. At the age of 35 days, all the follicles are formed and can be distinguished on the surface of the ovary. At the age of 45 days, slow growth of oocytes begins, and at the age of 55 days oocytes reach the phase of rapid growth; during this period, the ovary visually looks like a cluster, contains yellow-orange follicles of various sizes. The use of the probiotic preparation "Sporovit" and succinic acid does not cause pathological changes in the micromorphological structure of the reproductive organs of quails. 


\section{Conclusion}

The use of the probiotic drug "Sporovit" in combination with succinic acid to Texas quail at the age of 5-45 days in experimental group No 2 had a significant result in the development of the sexual apparatus, where the morphometric parameters of the reproduction organs are three times higher than in the control group. The use of the probiotic drug "Sporovit" without adding succinic acid to Texas quail at the age of 5-45 days in experimental group No 1 had less significant results, and the morphometric parameters of the breeding organs are two times lower than in experimental group No 2. In quails aged 45-55 days, the picture of the effect of the probiotic preparation "Sporovit " and succinic acid is directly opposite, the intensity of organ growth is significantly reduced when using the probiotic preparation "Sporovit " in experimental group No 1 and less significantly reduced when using the probiotic preparation "Sporovit " in combination with succinic acid in experimental group No 2. Probiotic preparation "Sporovit" and succinic acid do not cause pathological changes in the micromorphological structure of the reproduction organs of quails.

\section{References}

1. M. Tixier-Boichard, F. Leenstra, D. K. Flosk, P.M. Hocking, S. Weig-end, World's Poult. Sci. J., 68(2), 307-322 (2012) doi: 10.1017/S0043933912000360

2. C. Rong, C. Guobin, Q. Yurong, L. Bichun, C. Guohong, African Journal of Biotechnology, 10(4), 712-717 (2011) doi: 10.5897/AJB09.1519

3. A. Gupta, N. Bansal, V. Uppal, Int. J. Avian \& Wildlife Biol., 3(6), 423-425 (2018) doi: 10.15406/ijawb.2018.03.00134.

4. K. Bai, Q. Huang, J. Zhang, J. He, L. Zhang, T. Wang, Poult. Sci., 96(1), 74-82 (2017)

5. Y. A. Lysenko, A. V. Luneva, A. G. Koshchayev, K. P. Fedorenko, V. V. Petrova, Advances in Agricultural and Biological Sciences, 1(1), 3-10 (2015)

6. T. C. M. Woyengo. Can. J. Anim. Sci., 93(1), 9-21 (2013) doi: 10.4141/cjas2012-017

7. X. Liu, H. Yan, L. Lv, Q. Xu, Ch. Yin, K. Zhang, P. Wang, J. Hu, Asian-Australas. J. Anim. Sci., 25(5), 682-689 (2012) doi: 10.5713/ajas.2011.11334

8. R. Novak, B. Bogovič Matijašić, D. Terčič, M. Cervek, G. Gorjanc, A. Holcman, A. Levart, I. Rogelj, J. Anim. Physiol. Anim. Nutr., 95(4), 423-433 (2011) doi: 10.1111/j.1439-0396.2010.01068x

9. Y. Fan, L. Zhao, Q. Ma, X. Li, H. Shi, T. Zhou, J. Zhang, C. Ji, Food Chem. Toxicol. 59, 748-753 (2013) doi: 10.1016/j.fct.2013.07.010

10. Y. B. Li, Q. Xu, Z. Huang, L Lv, X. Liu, C. Yin, H. Yan, J. Yuan J. Appl, Microbiol., 120(1), 195-204 (2016) doi: 10.1111/jam.12972

11. A. G. Koshchaev, Y. A. Lysenko, O. V. Koshchaeva, Advances in Agricultural and Biological Sciences, 1 (2), 44-52 (2015).

12. H.W. Kim, F. F. Yan, J. Y. Hu, H. W. Cheng, Y. H. Kim, Poult. Sci., 95(6), $1457-$ 1464 (2016) doi: 10.3382/ps/pew055

13. S. M. Cutting, Food Microbiol., 28(2), 214-220 (2011) doi: 10.1016/j.fm.2010.03.007

14. G. G. Moran, Anat Rec., 294(5), 893-904 (2011)

15. F. Sinowatz, D. Rodler, Cells Tissues Organs, 197(4), 298-211 (2013)

16. A. Deka, K. Sarma, S. Sarma, et al., Journal of Agriculture and Veterinary Science, 8(2), 33-37 (2015) 
17. M. Hassan, S. Mehmood, M. Javed, et al., International Journal of Agriculture Applied Science, 5(2), 70-78 (2013)

18. E. S. Kigir, S. N. Sivachelvan, H. D. Kwari, et al., New York Science Journal, 3(10), 108-111(2010)

19. A. L. Shtele, Agricultural biology, 6, 26-35 (2014) doi: 10.15389/agrobiology.2014.6.26eng 